\title{
Quality of life and mental health among Thai older workers in community enterprises
}

\author{
Suda Hanklang \\ Faculty of Nursing, Vongchavalitkul University, Nakhon Ratchasima, Thailand \\ Paul Ratanasiripong \\ California State University, Long Beach, California, USA, and \\ Sarinya Naksranoi, Suchinda Sathira-Anant and Kalaya Patanasri \\ Faculty of Nursing, Vongchavalitkul University, Nakhon Ratchasima, Thailand
}

\section{Quality of life and mental health}

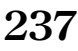

Received 7 November 2017 Accepted 5 February 2018

\begin{abstract}
Purpose - An aging society is a growing global reality resulting in an increasing number of older workers, especially in community enterprises. It is important to understand factors that influence the mental health and quality of life (QOL) of these older workers. The purpose of this paper is to explore the influence of personal, work, and mental health factors on the QOL among older workers in community enterprises.

Design/methodology/approach - This cross-sectional study examined the mental health and QOL of 387 older workers from three industries: food production, handicraft, and farm-related work. These participants formed a representative sample of the 19,200 members of the 1,184 groups in the community enterprise sector in Nakhon Ratchasima province. Stratified random sampling technique was used. Pearson's Product Moment Correlation Analysis was used to examine the factors associated with QOL. A multiple regression statistical model was used to examine the QOL predicting factors.

Findings - The response rate for this study was 93.25 percent. The majority of participants were female (73.4 percent). The majority of older workers were educated to primary school educational level (81.4 percent). The ratio of workers within each project included farm-related work (36.7 percent), handicraft (37.7 percent) and food production (25.6 percent). Most older workers (90.2 percent) had normal mental health based on their GHQ screening. The overall QOL average score was 88.43 (SD 10.43). The results suggested that the QOL is related to age, income, somatic symptoms, anxiety and insomnia, social dysfunction, severe depression, and mental health problems. Additionally, multiple regression analysis indicated social dysfunction and income were significant predictors for the QOL of older workers with $R^{2}=0.118, F=15.53(p<0.001)$.

Originality/value - With the results showing associations between personal factors and work factors relating to QOL, it is important for health professionals to pay attention to older workers' work environments, financial issues, and mental health.
\end{abstract}

Keywords Mental health, Quality of life, Older workers, Community enterprises

Paper type Research paper

\section{Background}

Informal workers are those who work without protection and security[1]. The types of informal work include community enterprises, household businesses, and freelance workers who are working to survive[2]. Currently, there are 21.3 million informal workers making up about 55 percent of the total labor force in Thailand[3]. Approximately 3.45 million older workers are employed, of which 3.1 million are employed in the informal sector[4].

(C) Suda Hanklang, Paul Ratanasiripong, Sarinya Naksranoi, Suchinda Sathira-Anant and Kalaya Patanasri. Published in the Journal of Health Research. Published by Emerald Publishing Limited. This article is published under the Creative Commons Attribution (CC BY 4.0) licence. Anyone may reproduce, distribute, translate and create derivative works of this article (for both commercial \& non-commercial purposes), subject to full attribution to the original publication and authors. The full terms of this licence may be seen at http://creativecommons.org/licences/by/4.0/legalcode

The authors would like to acknowledge Vongchavalitkul University for financial support for this study. The authors appreciate all the older workers in the community enterprises who participated in this study.

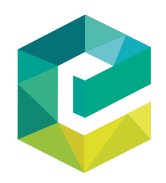

Journal of Health Research Vol. 32 No. 3, 2018 pp. $237-250$

Emerald Publishing Limited 2586-940X DOI 10.1108/JHR-05-2018-025 
JHR

32,3

According to the United Nations definition, a country with more than 10 percent of its population over 60 years old is considered to have entered the elderly society[5]. The National Statistical Office indicated that Thailand had entered the elderly society bracket since 2005. The current elderly population in Thailand is at 16.67 percent. It is expected that Thailand will be fully integrated into the aging society in 2025 , where the proportion of the aging population is projected to increase[6]. Older workers are generally defined as workers who are 45 years or older[7, 8]. This is because people generally have a maximum body capacity of about 25 years for work until the age of 50 years old, based on the deterioration of the body[8,9]. The physiological condition will change and increase the risk of diseases, including both physical and mental health problems[10].

The Northeastern region of Thailand has the highest prevalence of an older workforce. Nakhon Ratchasima province has the highest population in the Northeast area and the second highest population in the country. The Statistics Office of Nakhon Ratchasima province reported the population to be $2,808,574$, with 49.35 percent males and 50.65 percent females. The average life expectancy is 70.52 years for male and 76.79 years for female. The economic growth has continued with a Gross Domestic Product of 202,014 million Baht in 2011. The labor force was 1,632,424 people, or 73.99 percent of the population aged 15 and over. The workers' characteristics were home-based workers, self-employment, subcontracting, and community enterprises[11].

The term community enterprise was derived from the implementation of the community economy of informal workers and Sufficiency Economy Philosophy to develop continuously and systematically. Community enterprises have more emphasis on self-sufficiency than profit. It is a real economic base of the community[12]. If the community is strong and self-reliant, the economy of the country will be strong and stable.

Nakhon Ratchasima province has many natural resources distributed across its districts. There are 32 districts with 1,184 well-run community enterprise groups involved in pasteurized salted egg processing, rice cracker production, tissue box sewing, organic fertilizer development, and weaving. There are 19,200 members in the community enterprises in Nakhon Ratchasima province involved in processing a wide variety of community products, especially products that focus on unique community wisdom. There is a definite distribution market[11]. Some enterprises can produce products throughout the year. Standardized products are accepted by the market, such as Dan Kwian pottery, silk, Korat noodles, vegetables, and fruits. However, community enterprise is not a public organization, not under commercial law and the support system is not systematic and united. Informal workers in many of the existing community enterprises face work risks like other workers in the informal sector. The problems and obstacles in the work of the informal workers are manifold, including eye problems, fatigue, musculoskeletal problems, back pain, and muscle ache. Occupational health is poor, and concerns include restrictive workplace, hot air, dust, and prolonged posture[13]. Many workplace environments and conditions do not suit the physical condition of the older workers. Other problems they face include lack of succession, lack of bargaining power, unfair compensation, uncertain income, and debts[4].

Informal workers have a higher risk of illness or occupational injury due to the nature of their work with exposure to various health threats, such as chemical (agricultural chemicals), biological (germs), physical environment risk (light, heat), and psychological (stress). More importantly, the older workers in this group have lower levels of education and economic status than the general labor force who are protected by the Social Security Office; they also face lack of funding and self-care knowledge and the ability to access public health services[14]. Most of the older workers have non-standard working conditions and no 
official employment contract; they do not get a fair wage and are not covered by the Social Security Act 2010 and the Labor Protection Act BE 2541, making their employment unstable. There is also no security in life as they get older[2].

The literature review showed that occupational health and safety issues are major problems for informal workers, with 57 percent who were found to be experiencing poor work conditions and work environment, such as heavy lifting, working in postures that cause pain and working in dusty areas[15]. Most work environment problems and most injuries found were for working in hot weather (71 percent) and having sharp injuries (92 percent)[13]. Studies found informal workers to have moderately positive attitudes about health promotion (89 percent) and recommended doing health surveillance as well as promoting proper use of personal protective equipment (PPE) and personal health care to reduce health risks from work[16]. For quality of life (QOL) and mental health of informal workers, a study found that most informal workers (79 percent) had a moderate level of QOL. Factors related to QOL were health behaviors and family relationships[17]. Some studies found that the lowest QOL domain was the physical domain (38 percent), followed by environmental and social relationship[18].

Many older informal workers will soon enter their elderly years. However, there are no welfare benefits to help with health risks resulting from work as well as mental health and development of QOL in the future as they enter their elderly years. Therefore, this study examined the work risks of the older informal workers in community enterprises and examined factors that influence their mental health and QOL. The results of this study can be used by older informal workers in community enterprises but also by their families, as a means of preventing workplace risks, promote self-care, prevent physical health problems from work, promote mental health, and ultimately, to improve the quality of work life.

Research objectives are as follows: to study the demographic characteristics, work characteristics, and occupational health risks among older workers in community enterprises; to study the mental health and QOL among older workers in community enterprises; and to explore the influence of personal factors, work factors, and mental health factor on the QOL among older workers in community enterprises.

\section{Methods}

Study design

A cross-sectional research was conducted among older workers in community enterprises to assess their mental health and QOL. The researcher applied the concept of epidemiological theories, which identified the relationship of health status, health behavior and environment as well as the concept of occupational health and safety, particularly the assessment of risk factors.

Participants for this study were older workers in three community enterprise industries: food production, handicrafts, and farm-related work. The study population included female and male older informal workers who are members of the community enterprise group in Nakhon Ratchasima province. There are 1,184 community enterprise groups with 19,200 members in Nakhon Ratchasima.

Sample size. From the total of 19,200 members in 1,184 enterprise groups in 32 districts of Nakhon Ratchasima province, potential samples were selected from the districts with the highest members: Pak Thong Chai, Chokchai, and Khonburi Districts. Sample size estimation from Krejcie and Morgan's table for determining sample size from a given population was 377 persons[19]. Additional 10 percent were added to compensate for incomplete data, making the total sample size of 415 persons. 
JHR

32,3

240

Stratified sampling. Participants were randomly selected from the three districts with the same proportion (1: 11.51): Khonburi district (2,017 members), Pak Thong Chai district (1,349 members) and Chokchai district (1,410 members). Therefore, Khon Buri District included 175 older workers; Pak Thong Chai district included 117 older workers; and Chokchai district included 123 older workers. Next, the researcher randomly selected the community enterprise workers for data collection in each district, with equal numbers of older workers in the 3 community enterprise industries (food production, handicraft, and farm-related work) per district. For Khonburi district, each industry had 58 participants; for Pak Thong Chai district, each industry had 39 participants; and for Chokchai district, each industry had 41 participants. In total, there were 415 selected participants.

Final participant selection criteria for this study include these eight conditions: older worker who is at least 45 years old; works without formal employment contracts or has no employer under labor law; Thai nationality; works at least six months in community enterprise; has lived in the community for more than six months; able to answer questions, no problems speaking, listening and communicating; willing to volunteer to participate in this study; and able to sign the informed consent form.

\section{Research instruments}

The data collected in the research are as follows:

- Part 1: personal factors including age, gender, marital status, highest education level, occupation, income, and working year.

- Part 2: for health risk assessment, this study used the health risk assessment questionnaire developed by the Bureau of Occupational and Environmental Diseases, the Ministry of Health in 2010 which measures the occupation risk of informal workers[20]. The questionnaire included work risk perception, work behaviors, and health risk behaviors. There were 6 items with two levels of scores: 1 and 2 . Results were divided into three levels: low risk ( 6 to 7 points), medium risk (8 to 9 points), and high-risk (10 to 12 points). There were also three questions about the need for support to reduce the occupational health risks: knowledge, PPE, and health checkup.

- Part 3: the General Health Questionnaire (Thai GHQ 28) is one of the most widely accepted mental health screening instruments available in more than 36 languages. The Thai GHQ 28 is an acceptable screening test for mental health problems in the community with Cronbach's $\alpha$ coefficient between 0.84 and 0.94 in previous studies with the Thai population[21]. Cronbach's $\alpha$ coefficient for this study was found to be 0.90. The Thai GHQ 28 assessed the health status in the past 2-3 weeks; a score of 6 points or more is considered to be abnormal mental health. The Thai GHQ 28 is divided into four symptom areas: somatic symptoms; anxiety and insomnia; social dysfunction; and severe depression.

- Part 4: QOL over the past two weeks is assessed by the World Health Organization Quality of Life Scale (WHOQOL-BREF-Thai). The WHOQOL project was initiated in 1991 with the aim of developing an international cross-culturally comparable QOL assessment instrument[22]. This 26-question, five-level scale is easy to understand and takes minimal time to complete[22]. The overall scores for the QOL range from 26 to 130 points. Overall scores can be compared with the following criteria which has already been validated among Thai people[23]: scores between 26-60 indicate poor QOL; scores between 61-95 indicate moderate QOL; scores between 96-130 indicate good QOL[24]. Cronbach's $\alpha$ coefficient of WHOQOL-BREF-Thai for this study was found to be 0.88 . More specifically, the WHOQOL-BREF-Thai consisted of 4 domains: Physical domain (7 items) is the perception of the physical condition which affected 
daily activities; Psychological domain (6 items) is the mental self-perception; Social relationships domain (3 items) is the perception of their relationships with others; Environment domain (8 items) is the perception effect of the environment.

Content validity. A panel of three experts assessed the content validity of the questionnaires. The experts included one specialist for older workers' health (adult and aging health nurse), one psychiatric specialist, and one occupational health nurse. The suggestions item sentence was revised in accordance to the main concept of measure and made easier to understand.

Quality of life and mental health

Reliability. The questionnaires were tested for reliability with 30 older workers who have similar characteristics as the potential participants. The purpose was to check the correctness of the statement and to evaluate the time used for answering the questionnaires. For internal consistency reliability testing, Cronbach's $\alpha$ coefficient was analyzed.

\section{Data collection processes}

The data collection process is described below: first, data collection started after receiving approval from the Committee of Human Ethical Research, Maharat Hospital Nakhon Ratchasima. Ethics Code 096/2016; second, permission was submitted to the administrator of the Provincial Health Office who coordinated with the chair of the community enterprise in Nakhon Ratchasima. The researcher coordinated with the community enterprise in each district. Third, the researchers trained the data collection team to use the questionnaires, including how to obtain informed consent and provide basic assistance when the participant was found to be at risk. Fourth, researchers traveled to the area to collect data. The village health volunteers assisted the research team with access to participants to collect data. The participants were invited for interview during their break time, after lunch, or after work in the resting zone or break area of their enterprises. Fifth, results of all responses and information are confidential and only used for research and educational purposes. Sixth, the questionnaire included 72 questions. Participants completed the questionnaire in an average of 45 minutes. Seventh, when the questionnaire was completed, the researcher verified the completeness of the information obtained from the responses, then recorded and analyzed the data.

Statistical Packet for the Social Sciences 23.0 was used for data analyses. Descriptive statistics were used to describe participants' personal and work characteristics. Pearson correlation coefficients were used to explore relationships between demographic variables and work, mental health, and QOL. Multiple regression analyses were used to test the predictability of personal, work, and mental health factors on the QOL among older workers.

\section{Results}

A total of 387 participants completed the questionnaires, including 73.4 percent females and 26.6 percent males. The average age was $54.74(\mathrm{SD}=7.82$, range $=45-80)$. The majority of the older workers (81.4 percent) were educated up to primary school level. Most participants (81.7 percent) were married. The majority of participants (71.1 percent) had a monthly income of 5,000 Baht or less. Most participants did not smoke (89.0 percent) and did not use alcohol (82.4 percent). Older workers' work characteristics, work risks, and work risk scores are indicated in Table I.

Regarding support needed among older workers, 94.3 percent indicated that they needed some kind of support. Specifically, many participants expressed the need for safety concept knowledge (47.5 percent), chemical safety knowledge (25.6 percent), knowledge for risk of work hazards (22.7 percent), and knowledge for work hazard and risk prevention (21.2 percent). Several participants also indicated the need for PPE, including goggles (26.4 percent), protective masks (54.3 percent), protective gloves (54.0 percent), and boots (34.9 percent). During the physical health checkup, many participants expressed the need for 
Work factors

Number (\%)

Work characteristics

Farm-related work

Handcraft

Food production

242

Working year $($ Mean $=27.08, S D$ 13.252)

$142(36.7)$

$146(37.7)$

$99(25.6)$

5-10

11-15

16-20

21-25

26-30

31-35

36-40

41 and more

Work risks perception

Yes

Not sure

No

64 (16.5)

$29(7.5)$

$39(10.1)$

$49(12.7)$

$69(17.8)$

$35(9.0)$

$59(15.2)$

$43(11.1)$

Dust

No

Yes

Chemicals

No

Yes

Noise

No

Yes

Heat

No

Yes

Light

No

Yes

Musculoskeletal injury

No

Yes

366 (94.6)

$10(2.6)$

$11(2.8)$

215 (55.6)

$172(44.4)$

$246(63.6)$

141 (36.4)

378 (97.7)

$9(2.3)$

$253(65.4)$

134 (34.6)

372 (96.1)

$15(3.9)$

199 (51.4)

188 (48.6)

Biological risks

No

$399(87.6)$

Yes

$48(12.4)$

Other

No

381 (98.4)

6 (1.6)

Risk concerns

All the time

$116(30.0)$

Frequently

$180(46.5)$

Sometimes

$91(23.5)$

Risk prevention

All the time

$136(35.1)$

Frequently

$202(52.2)$

Sometimes

$49(12.7)$

Work risk score (range score $=6-12$ )

Low (6-7)

$267(69.0)$

Moderate (8-9)

Work factors

High (10-12)

$105(27.1)$

Note: $n=387$ 
annual health checks (56.1 percent) and health checkup based on risk factors (38.5 percent). Most older workers (90.2 percent) had normal mental health based on the GHQ screening. Few had somatic symptoms (2.3 percent), anxiety and insomnia (0.8 percent), social dysfunction (1.3 percent), and severe depression ( 0.8 percent). Table II showed the level of QOL of older workers including scores on the four domains.

For the bivariate analysis of personal variables, overall QOL mean values were lower for female $(p=0.040)$, individuals between 61 and 70 years $(p=0.007)$, education to primary school level $(p=0.020)$, monthly income less than 5,000 Baht $(p<0.001)$, and having at least one chronic disease $(p=0.016)$. See Table III for additional results of personal variables for the QOL physical, psychosocial, social relationships, and environment domains. For the bivariate analysis of work variables, overall QOL mean values were lower for work risk perception for heat $(p=0.009)$ and biologicals ( $p$-value $=0.016)$. See Table IV for additional results of work variables for the QOL physical, psychosocial, social relationships, and environment domains. For the bivariate analysis of mental health $(\mathrm{GHQ})$ variables, overall QOL mean values were lower for total score of abnormal mental health $(p<0.001)$ and social dysfunction $(p=0.001)$. See Table $\mathrm{V}$ for additional results of mental health variables for the QOL physical, psychosocial, social relationships, and environment domains.

The zero-order correlations ranged from 0.005 to 0.818 (Table VI). Results suggested that when age increased, income decreased, somatic symptoms increased, anxiety and insomnia increased, social dysfunction increased, severe depression increased, total score of mental health problems increased, and QOL decreased. Further, the correlations suggested that respondents with higher age reported lower income. Respondents who had higher working years reported higher total work risk score, higher somatic symptoms, higher anxiety and insomnia, and higher social dysfunction.

\begin{tabular}{|c|c|c|c|}
\hline Quality of life & Number & $(\%)$ & \\
\hline \multicolumn{4}{|c|}{ QOL: physical domain } \\
\hline Poor & 3 & 0.8 & \\
\hline Moderate & 298 & 77.0 & \\
\hline Good & 86 & 22.2 & \\
\hline \multicolumn{4}{|c|}{ QOL: psychosocial domain } \\
\hline Poor & 9 & 2.3 & \\
\hline Moderate & 206 & 53.2 & \\
\hline Good & 172 & 44.4 & \\
\hline \multicolumn{4}{|c|}{ QOL: social relationship domain } \\
\hline Poor & 45 & 11.6 & \\
\hline Moderate & 298 & 77.0 & \\
\hline Good & 44 & 11.4 & \\
\hline \multicolumn{4}{|c|}{ QOL: environment domain } \\
\hline Poor & 5 & 1.3 & \\
\hline Moderate & 321 & 82.9 & \\
\hline Good & 61 & 15.8 & \\
\hline \multicolumn{4}{|l|}{ QOL (Total) } \\
\hline Poor & 2 & 0.5 & \\
\hline Moderate & 305 & 78.8 & \\
\hline Good & 80 & 20.7 & \\
\hline \multicolumn{3}{|c|}{ Notes: $n=387$. Min-Max score $=43-120$, Mean $=88.43, \mathrm{SD}=10.437$} & Quality of life \\
\hline
\end{tabular}

Quality of life and mental health

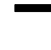


Table III.

Bivariate association (mean differences) between personal variables and quality of life (QOL) among older workers in community enterprise

\begin{tabular}{|c|c|c|c|c|c|}
\hline \multirow[b]{2}{*}{ Variables } & \multicolumn{5}{|c|}{ WHOQOL-BREF scores (Mean (SD)) } \\
\hline & Overall QOL & Physical & Psychological & Social relationships & Environment \\
\hline \multicolumn{6}{|l|}{ Gender } \\
\hline Male & $90.24(12.03)$ & $24.90(3.45)$ & $22.80(3.75)$ & $9.55(1.80)$ & $26.44(4.41)$ \\
\hline Female & $87.78(9.74)$ & $23.46(3.13)$ & $21.53(3.34)$ & $9.66(1.59)$ & $26.56(3.94)$ \\
\hline$p$-value & 0.040 & $<0.001$ & 0.002 & 0.579 & 0.793 \\
\hline \multicolumn{6}{|l|}{ Age (years) } \\
\hline $45-50$ & 89.35 (10.68) & $24.17(3.24)$ & $22.16(3.50)$ & $9.74(1.68)$ & $26.66(4.15)$ \\
\hline $51-60$ & 87.80 (10.63) & $23.84(3.28)$ & $21.60(3.60)$ & $9.57(1.56)$ & $26.32(4.05)$ \\
\hline $61-70$ & $85.94(7.99)$ & $22.53(2.49)$ & $21.15(2.99)$ & $9.50(1.62)$ & $26.00(3.83)$ \\
\hline $71-80$ & $86.18(8.80)$ & $21.73(4.56)$ & 21.64 (3.44) & $8.73(1.90)$ & 28.09 (3.33) \\
\hline$p$-value & 0.007 & 0.289 & 0.202 & 0.429 & 0.207 \\
\hline \multicolumn{6}{|l|}{ Highest education } \\
\hline No education & $88.60(10.60)$ & $25.00(0.00)$ & $21.60(23.80)$ & $9.80(2.28)$ & $26.00(3.08)$ \\
\hline Primary school & $87.82(10.62)$ & $23.60(3.32)$ & $21.66(3.50)$ & $9.58(1.68)$ & $26.48(4.19)$ \\
\hline Secondary school & $91.71(10.03)$ & $25.11(3.16)$ & 23.16 (3.13) & 9.73 (1.34) & $26.80(3.73)$ \\
\hline High school and higher & $90.50(6.96)$ & $24.45(2.52)$ & $22.23(3.49)$ & $10.05(1.59)$ & $26.73(3.13)$ \\
\hline$p$-value & 0.020 & 0.058 & 0.599 & 0.945 & 0.093 \\
\hline \multicolumn{6}{|l|}{ Income } \\
\hline$\leqslant 5,000$ & $88.84(9.85)$ & $23.17(3.05)$ & $21.19(3.41)$ & $9.58(1.60)$ & $26.39(3.94)$ \\
\hline $5,001-10,000$ & 92.29 (11.07) & 25.42 (3.13) & 23.45 (3.25) & $9.81(1.87)$ & $26.96(4.50)$ \\
\hline $10,001-15,000$ & 92.95 (12.04) & $26.42(3.64)$ & 23.53 (3.24) & 9.74 (1.28) & $26.47(4.36)$ \\
\hline $15,001-20,000$ & $91.50(4.80)$ & $23.00(3.65)$ & $24.50(0.58)$ & $10.00(1.41)$ & $27.25(4.34)$ \\
\hline$>20,000$ & $91.25(4.50)$ & $25.25(3.30)$ & $24.25(2.22)$ & 8.50 (1.29) & 26.50 (1.73) \\
\hline$p$-value & $<0.001$ & $<0.001$ & 0.482 & 0.837 & $<0.001$ \\
\hline \multicolumn{6}{|l|}{ Marital status } \\
\hline Single & 88.19 (10.25) & $23.38(2.66)$ & $21.69(2.77)$ & $9.75(2.15$ & $26.75(4.57)$ \\
\hline Married & $88.76(10.02)$ & $23.92(3.30)$ & 21.89 (3.44) & 9.05 (1.74) & $25.75(4.96)$ \\
\hline Widowed/divorced & 86.62 (12.63) & 23.53 (3.33) & 21.76 (4.02) & 9.05 (1.75) & $25.75(4.96)$ \\
\hline$p$-value & 0.599 & 0.948 & 0.019 & 0.305 & 0.371 \\
\hline \multicolumn{6}{|l|}{ Diseases or illnesses } \\
\hline & 89.60 (11.05) & $24.61(3.29)$ & 22.24 (3.59) & $9.62(1.60)$ & $26.48(4.28)$ \\
\hline Yes & $87.05(9.50)$ & $22.94(3.04)$ & 21.42 (3.33) & $9.64(1.70)$ & $26.58(4.07)$ \\
\hline$p$-value & 0.016 & $<0.001$ & 0.021 & 0.931 & 0.808 \\
\hline \multicolumn{6}{|l|}{ Smoking } \\
\hline & 88.33 (10.43) & $23.77(3.27)$ & 21.76 (3.48) & 9.66 (1.65) & $26.53(4.09)$ \\
\hline Yes & 89.12 (10.59) & 24.36 (3.32) & 22.58 (3.57) & $9.42(1.63)$ & $26.50(3.94)$ \\
\hline$p$-value & 0.234 & 0.122 & 0.333 & 0.960 & 0.619 \\
\hline \multicolumn{6}{|l|}{ Alcohol } \\
\hline & $88.32(9.36)$ & $23.73(3.15)$ & 21.74 (3.35) & $9.68(1.58)$ & $26.52(3.72)$ \\
\hline Sometime & 90.50 (13.64) & $24.50(3.67)$ & $22.85(3.80)$ & $9.65(1.87)$ & $27.09(5.21)$ \\
\hline Often & 81.06 (9.41) & 23.00 (3.43) & $19.56(3.42)$ & 8.69 (1.45) & $24.00(3.56)$ \\
\hline$p$-value & 0.111 & 0.001 & 0.063 & 0.022 & 0.004 \\
\hline Note: $n=387$ & & & & & \\
\hline
\end{tabular}

When analyzing the factors influencing QOL using multiple regression analysis, the dependent variable: total score of QOL, independent variables entered: age, income, working year, total working risk score, somatic symptoms, anxiety and insomnia, social dysfunction, severe depression, total score of $\mathrm{GHQ}$, the results showed that social dysfunction ( $\beta=-0.289$, with $95 \% \mathrm{CI}-3.87$ to -1.97 ) and income ( $\beta=0.189$ with $95 \% \mathrm{CI}: 0.00$ to 0.001 ) 


\begin{tabular}{|c|c|c|c|c|c|c|}
\hline \multirow[b]{2}{*}{ Variables } & \multirow[b]{2}{*}{ Overall QOL } & \multicolumn{3}{|c|}{ WHOQOL-BREF scores (Mean (SD)) } & \multirow[b]{2}{*}{ Environment } & \\
\hline & & Physical & Psychological & Social relationships & & and mental \\
\hline \multicolumn{7}{|l|}{ Work characteristics } \\
\hline Farm-related work & 89.26 (13.68) & 24.07 (3.54) & 22.52 (3.96) & $9.46(1.95)$ & $26.81(5.31)$ & \\
\hline Handcraft & $88.29(8.51)$ & $24.15(3.11)$ & $21.82(2.97)$ & $9.72(1.37)$ & $25.94(3.53)$ & \\
\hline Food production & $87.45(7.12)$ & 23.07 (3.04) & $21.00(3.34)$ & $9.73(1.37)$ & $26.99(2.31)$ & \\
\hline$p$-value & 0.410 & 0.024 & 0.004 & 0.320 & 0.081 & 245 \\
\hline \multicolumn{7}{|l|}{ Working year } \\
\hline $5-25$ & $88.08(10.62)$ & $23.67(3.31)$ & $21.56(3.45)$ & $9.72(1.74)$ & $26.49(3.86)$ & \\
\hline 26 and more & $88.74(10.29)$ & $24.00(3.25)$ & $22.14(3.52)$ & $9.55(1.56)$ & $26.56(4.25)$ & \\
\hline$p$-value & 0.536 & 0.322 & 0.105 & 0.326 & 0.873 & \\
\hline \multicolumn{7}{|l|}{ Work risks perception } \\
\hline Yes & 88.43 (10.27) & $23.85(3.29)$ & $21.86(3.50)$ & $9.63(1.65)$ & $26.53(3.97)$ & \\
\hline Not sure & $94.30(17.01)$ & $25.40(3.63)$ & $24.10(3.73)$ & $10.20(2.10)$ & $27.4(7.85)$ & \\
\hline No & $83.27(5.53)$ & $22.27(1.90)$ & $19.90(1.87)$ & $9.27(0.65)$ & $25.63(2.62)$ & \\
\hline$p$-value & 0.053 & 0.091 & 0.023 & 0.424 & 0.611 & \\
\hline \multicolumn{7}{|l|}{ Dust } \\
\hline No & 87.54 (10.51) & $24.03(3.45)$ & $22.04(3.37)$ & $9.30(1.70)$ & $25.73(4.10)$ & \\
\hline Yes & 89.55 (10.27) & $23.61(3.04)$ & $21.65(3.65)$ & $10.05(1.48)$ & $27.52(4.07)$ & \\
\hline$p$-value & 0.061 & 0.209 & 0.281 & $<0.001$ & $<0.001$ & \\
\hline \multicolumn{7}{|l|}{ Chemicals } \\
\hline No & 87.70 (10.47) & $23.94(3.40)$ & $22.02(3.34)$ & $9.36(1.64)$ & $26.02(4.15)$ & \\
\hline Yes & $89.70(10.30)$ & $23.68(3.07)$ & $21.59(3.76)$ & $10.11(1.55)$ & $27.42(3.76)$ & \\
\hline$p$-value & 0.070 & 0.457 & 0.239 & $<0.001$ & 0.001 & \\
\hline \multicolumn{7}{|l|}{ Noise } \\
\hline No & $88.50(10.40)$ & $23.83(3.28)$ & $21.91(3.44)$ & $9.63(1.64)$ & $26.54(4.10)$ & \\
\hline Yes & $85.56(12.30)$ & $24.44(3.17)$ & $20.00(5.45)$ & $9.56(1.74)$ & $25.89(2.57)$ & \\
\hline$p$-value & 0.403 & 0.580 & 0.105 & 0.890 & 0.634 & \\
\hline \multicolumn{7}{|l|}{ Heat } \\
\hline No & $89.43(10.19)$ & $23.92(3.25)$ & $21.89(3.49)$ & $9.92(1.56)$ & $26.94(3.92)$ & \\
\hline Yes & $86.54(10.68)$ & $23.70(3.34)$ & $21.83(3.52)$ & 9.09 (1.67) & $25.75(4.23)$ & \\
\hline$p$-value & 0.009 & 0.532 & 0.879 & $<0.001$ & 0.006 & \\
\hline \multicolumn{7}{|l|}{ Light } \\
\hline No & $88.52(10.52)$ & $23.78(3.30)$ & $21.85(3.53)$ & $9.66(1.65)$ & $26.66(4.04)$ & \\
\hline Yes & $86.27(8.20)$ & $25.40(2.44)$ & $22.13(2.72)$ & $9.00(1.31)$ & $23.33(3.35)$ & \\
\hline$p$-value & 0.413 & 0.061 & 0.763 & 0.130 & 0.002 & \\
\hline \multicolumn{7}{|c|}{ Musculoskeletal injury } \\
\hline No & $87.78(8.56)$ & $22.85(2.43)$ & $20.83(3.01)$ & $10.04(1.45)$ & $27.27(3.55)$ & \\
\hline Yes & 89.13 (12.07) & $24.90(3.71)$ & $22.96(3.65)$ & $9.20(1.73)$ & $25.74(4.42)$ & \\
\hline$p$-value & 0.204 & $<0.001$ & $<0.001$ & $<0.001$ & $<0.001$ & \\
\hline \multicolumn{7}{|l|}{ Biologicals } \\
\hline No & $88.91(10.70)$ & $24.04(3.35)$ & $22.13(3.50)$ & $9.61(1.66)$ & $26.55(3.10)$ & \\
\hline Yes & $85.04(7.610$ & $22.50(2.32)$ & $19.98(2.84)$ & $9.75(1.54)$ & $26.38(3.10)$ & \\
\hline$p$-value & 0.016 & 0.002 & $<0.001$ & 0.591 & 0.782 & \\
\hline \multicolumn{7}{|l|}{ Other } \\
\hline No & 88.43 (10.48) & $23.80(3.27)$ & $21.86(3.51)$ & $9.64(1.64)$ & $26.56(4.08)$ & \\
\hline Yes & $88.83(8.33)$ & $26.50(3.08)$ & $22.33(2.50)$ & 9.17 (1.94) & $24.17(4.07)$ & \\
\hline$p$-value & 0.925 & 0.045 & 0.742 & 0.487 & 0.152 & Table II \\
\hline Risk concerns & & & & & & Bivariate association \\
\hline All the time & $89.73(14.12)$ & $24.78(3.81)$ & $22.81(4.16)$ & $9.21(1.86)$ & $26.52(5.23)$ & (mean differences) \\
\hline Often & $87.15(7.11)$ & 23.04 (2.63) & $20.80(2.68)$ & $9.96(1.46)$ & $26.66(3.07)$ & between work \\
\hline Sometime & $89.32(10.27)$ & $24.24(3.36)$ & $22.77(3.43)$ & $9.52(1.59)$ & $26.29(4.14)$ & variables and quality \\
\hline$p$-value & 0.075 & $<0.001$ & $<0.001$ & 0.001 & 0.779 & of life (QOL) among \\
\hline & & & & & (continued) & $\begin{array}{l}\text { community } \\
\text { enterprises }\end{array}$ \\
\hline
\end{tabular}




Variables Overall QOL Physical Psychological Social relationships Environment

$\begin{array}{llccccc} & \text { Risk prevention } & & & & \\ & \text { All the time } & 89.65(13.11) & 24.50(3.32) & 22.63(3.95) & 9.26(1.80) & 26.71(5.14) \\ & \text { Often } & 87.70(8.01) & 23.30(2.85) & 21.17(3.14) & 9.92(1.43) & 26.67(3.15) \\ & \text { Sometime } & 88.08(10.82) & 24.29(4.34) & 22.61(2.99) & 9.45(1.82) & 25.45(3.97) \\ \text { p-value } & 0.237 & 0.002 & <0.001 & 0.001 & 0.139 \\ & \text { Total work risk } & & & & & \\ \text { Low } & 88.46(9.92) & 23.73(3.10) & 21.59(3.45) & 9.73(1.63) & 26.72(3.90) \\ \text { Moderate } & 88.50(11.91) & 24.03(3.77) & 22.46(3.58) & 9.51(1.70) & 26.18(4.52) \\ & \text { High } & 87.53(8.76) & 24.67(2.77) & 22.67(3.29) & 8.67(1.18) & 25.60(3.38) \\ & p \text {-value } & 0.943 & 0.446 & 0.064 & 0.035 & 0.349\end{array}$

Table IV.

Note: $n=387$

\section{Table V.}

Bivariate association (mean differences) between mental health $(\mathrm{GHQ})$ variables and quality of life (QOL) among older workers in community enterprise

\begin{tabular}{|c|c|c|c|c|c|}
\hline \multirow[b]{2}{*}{ Variables } & \multicolumn{5}{|c|}{ WHOQOL-BREF scores (Mean, SD) } \\
\hline & Overall QOL & Physical & Psychological & Social relationships & Environment \\
\hline \multicolumn{6}{|l|}{ Total score } \\
\hline Abnormal & $81.82(12.05)$ & $21.39(3.38)$ & $20.55(4.14)$ & $8.92(1.88)$ & $25.61(5.36)$ \\
\hline Normal & $89.15(10.00)$ & $24.11(3.16)$ & $22.01(3.40)$ & $9.71(1.60)$ & $26.63(3.90)$ \\
\hline$p$-value & $<0.001$ & $<0.001$ & 0.015 & 0.005 & 0.141 \\
\hline \multicolumn{6}{|c|}{ Somatic symptoms } \\
\hline Abnormal & $83.44(6.67)$ & $21.56(1.88)$ & $21.22(1.72)$ & $9.67(1.66)$ & $25.89(3.82)$ \\
\hline Normal & 88.55 (10.43) & $23.90(3.29)$ & $21.88(3.53)$ & $9.63(1.65)$ & $26.54(4.08)$ \\
\hline$p$-value & 0.147 & 0.034 & 0.577 & 0.947 & 0.634 \\
\hline \multicolumn{6}{|c|}{ Anxiety and insomnia } \\
\hline Abnormal & $84.67(10.50)$ & $23.67(3.06)$ & $21.67(3.51)$ & $9.00(1.00)$ & $24.67(4.62)$ \\
\hline Normal & 88.46 (10.44) & $23.84(3.28)$ & $21.87(3.50)$ & $9.64(1.65)$ & $26.53(4.07)$ \\
\hline$p$-value & 0.531 & 0.925 & 0.921 & 0.506 & 0.427 \\
\hline \multicolumn{6}{|c|}{ Social dysfunction } \\
\hline Abnormal & $72.40(9.63)$ & $18.40(5.86)$ & $18.60(4.34)$ & $8.00(1.00)$ & $22.40(3.78)$ \\
\hline Normal & 88.64 (10.29) & $23.92(3.18)$ & $21.90(3.47)$ & $9.65(1.64)$ & $26.58(4.05)$ \\
\hline$p$-value & 0.001 & $<0.001$ & 0.035 & 0.025 & 0.022 \\
\hline \multicolumn{6}{|c|}{ Severe depression } \\
\hline Abnormal & $82.33(9.29)$ & $22.00(2.00)$ & $20.00(3.00)$ & $9.33(0.58)$ & $26.53(4.05)$ \\
\hline Normal & 88.48 (10.44) & $23.86(3.28)$ & $21.88(3.50)$ & $9.63(1.64)$ & $26.53(4.07)$ \\
\hline$p$-value & 0.310 & 0.329 & 0.354 & 0.754 & 0.822 \\
\hline \multicolumn{6}{|c|}{ Note: $n=387$} \\
\hline
\end{tabular}

were significant predictors for QOL of older workers ( $p$-value $<0.001)$. These two predictors explains 11.8 percent of the influence on QOL of older workers. $(F=15.53, p<0.001$, $R^{2}=0.118$, adjusted $R^{2}=0.113$ ) (Table VII).

\section{Discussion}

A total of 387 questionnaire sheets were collected. The response rate was 93.25 percent. There were some non-responses in this study, in spite of the researcher setting the meeting and introducing the research study to the participants, explaining the purposes of the 
research and requesting their cooperation in answering the questionnaires for all older workers in each enterprise. Some participants left work earlier while some refused to participate even though the consent and rights of research participants were described with an opportunity to ask questions regarding what was not fully understood.

The search for QOL has received increasing interests from society, especially from health personnel who often feel responsible to promote health for the population to extend its longevity with a healthy QOL. The results showed that 20.7 percent of older workers had good QOL while 78.8 percent showed moderate QOL and only 0.5 percent showed poor QOL. Overall, the results might indicate that older workers in these communities had positive work characteristics such as a flexible work schedule that allows them to easily take care of their family. This is consistent with the study on QOL of informal workers in Bangkok which found that most workers (78.9 percent) had a moderate QOL[17]. Another study of the QOL of informal workers in Muang District, Lamphun province, found that 68.4 percent of informal workers enjoyed a moderate QOL while 47.7 percent had good mental health and 37.7 percent had good social relations[18]. The QOL of the elderly in Phitsanulok Municipality (most of them engaged in informal labor) was found to be moderate; the overall QOL of the female elderly was significantly higher than that of the male elderly[25]. The high QOL of older workers may be because they enjoy a higher degree of autonomy and control over their work schedule. In addition, older workers tend to be more satisfied with the balance of work activities and family/community involvement[26]. The work environment is an important factor that contributes to worker well-being in all age groups[27]. Our results showed work factors such as work characteristics, work risk perception, work risk concern associated with QOL, to be congruent with results of a study with SME workers in Indonesia[28].

\begin{tabular}{|c|c|c|c|c|c|c|c|c|c|c|}
\hline Variables & 1 & 2 & 3 & 4 & 5 & 6 & 7 & 8 & 9 & 10 \\
\hline 1. Age & 1 & & & & & & & & & \\
\hline 2. Working year & $0.409 * *$ & 1 & & & & & & & & \\
\hline 3. Income & $-0.115^{*}$ & 0.073 & 1 & & & & & & & \\
\hline 4. Total work risk score & 0.076 & $0.148 * *$ & 0.062 & 1 & & & & & & \\
\hline 5. Somatic symptoms & 0.084 & $0.240 * *$ & 0.082 & $0.217^{* *}$ & 1 & & & & & \\
\hline $\begin{array}{l}\text { 6. Anxiety and } \\
\text { insomnia }\end{array}$ & 0.005 & $0.140 * *$ & 0.035 & 0.066 & $0.521 * *$ & 1 & & & & \\
\hline 7. Social dysfunction & 0.032 & $0.158^{* *}$ & 0.012 & $0.148^{* *}$ & $0.469^{* *}$ & $0.581^{* *}$ & 1 & & & \\
\hline 8. Severe depression & -0.050 & 0.068 & 0.044 & $0.146 * *$ & $0.217 * *$ & $0.428 * *$ & $0.579 * *$ & 1 & & \\
\hline 9. Total score of GHQ & 0.040 & $0.215^{* *}$ & 0.061 & $0.194^{* *}$ & $0.807 * *$ & $0.820 * *$ & $0.818^{* *}$ & $0.610^{* *}$ & 1 & \\
\hline 10. Total score of QOL & $-0.101^{*}$ & 0.005 & $0.185^{* *}$ & -0.019 & $-0.151^{* *}$ & $-0.218^{* * *}$ & $-0.287 * *$ & -0.210 ** & $-0.268^{* * *}$ & 1 \\
\hline
\end{tabular}

Notes: $n=387 . * p<0.05 ; * p<0.01$

Quality of life and mental health

Table VI.

Variables associated with QOL by Pearson's correlation coefficients

\begin{tabular}{lrrrrrrr}
\hline & & & & & & \multicolumn{2}{c}{$95 \%$ C.I.for EXP $(B)$} \\
Predictors & $B$ & S.E. & Exp. $(B)$ & $t$ & $p$-value & Lower & Upper \\
\hline Constant & 87.094 & 0.771 & - & 112.952 & $<0.001$ & 85.578 & 88.610 \\
Social dysfunction & -2.916 & 0.484 & -0.289 & -6.028 & $<0.001$ & -3.867 & -1.965 \\
Income & 0.000 & 0.000 & 0.189 & 3.940 & $<0.001$ & 0.000 & 0.001
\end{tabular}

Notes: $n=387$. Dependent variable: total score of QOL; Independent variables entered: age, income, working year, total working risk score, somatic symptoms, anxiety and insomnia, social dysfunction, severe depression, total score of $\mathrm{GHQ}$

Table VII. Multiple regression analysis for predicting the QOL 
JHR

32,3

248

Regarding mental health, this study also showed that the majority of respondents had good mental health scores in all domains. This supports a recent study which found that work status was one of the key determinants of mental health. Elderly people who were still working enjoyed better mental health than elderly who did not work[29]. In this study, social dysfunction and income have only a very weak association with QOL as shown in Table VI whereas these two mentioned variables can predict the QOL. Social dysfunction was a negative influencing factor for QOL among older workers with higher social dysfunction causing lower QOL. This result extended the links from previous studies that found depression as negative influence factor and life satisfaction as positive influence factor for QOL[30]. Regarding income, most informal workers in Thailand had lower income per month than other workers, about 2.2 times lower than the average 6,691 Baht per month[3]. For this study, income was the predictor for QOL among older workers in community enterprises. These results are consistent with conditions of other older workers around the world where literature showed the hiring rates of older workers tend to be much lower than those of other age groups[31].

\section{Conclusion}

The research objective of this study was to examine the work risks of older informal workers in community enterprises and factors that influence their mental health and QOL. Results showed the majority of older workers were female; work risks included dust, chemicals, heat, and musculoskeletal injury; the majority of older workers had a moderate QOL and good mental health. Personal characteristics, especially age, income and some mental health problems correlated with QOL. Social dysfunction and income can also predict the QOL of individuals. Health professionals can start by helping older workers improve social functioning to help improve their QOL. The hope is that older workers will maintain healthy QOL as they move into their retirement years. Finally, the results of this study showed associations between personal factors and work factors with QOL. Therefore, it is important to pay attention to older workers' work environments, income, and mental health.

\section{References}

1. National Statistical Office, Thailand. Social situation and outlook. 2012; [update 2012 Jan 10; cited 2017 Oct 24]. Available from: www.nso.go.th/sites/2014

2. Informal Labor Network Association, Thailand. The quality of life development for informal workers are the Thai people development. 2013; [update 2013 Mar 23; cited 2017 Oct 28]. Available from: www.thaitechno.net/t1/home.php?uid=45911

3. National Statistical Office, Thailand. Summary of workers survey. 2016; [update 2017 Jan 6; cited 2017 Oct 28]. Available from: http:/service.nso.go.th/nso/nsopublish/themes/files/workerOutEx c59.pdf

4. Wongphrom C, Yenbumrong T, Jongwuttivate K, Choawakul M, Maneerat S. The research on mechanisms for promotion of employment of older persons who are informal laborers. 2015; Institute of Research and Development, Khon Kaen University, Khon Kaen.

5. World Health Organization (WHO). Proposed working definition of an older person in Africa for the MDS project: health statistics and information systems. 2002; [update 2015 Jul; cited 2017 Jan 28]. Available from: www.who.int/healthinfo/survey/ageingdefnolder/en/

6. Ministry of Social Development and Human Security, Thailand. Thai elderly. 2015; [update 2015 Nov; cited 2017 Jan 20]. Available from: www.m-society.go.th/article_attach/13225/17347.pdf

7. Canadian Centre for Occupational Health and Safety. Aging workers. 2012; [update 2015; cited 2017 Oct 28]. Available from: www.ccohs.ca/oshanswers/psychosocial/aging_workers.html 
8. Hurwitz S, Allen J, Liben A, Becklake MR. Lung function in young adults: evidence for differences in the chronological age at which various functions start to decline. Thorax. 1980 Aug; 35(8): 615-9.

9. Demakakos P, Gjonca E, Nazroo J. Age identity, age perceptions, and health: evidence from the English longitudinal study of ageing. Ann N Y Acad Sci. 2007; 1114(1): 279-87.

10. World Health Organization (WHO). Aging and work capacity: report of who study group. 1993; WHO, Geneva.

Quality of life and mental health

11. Nakhon Ratchasima Statistics Development Plan. Site level statistical development plan: potential and strategic issues for provincial development. 2014; National Statistical Office, Thailand, Bangkok (in Thai).

12. Committee on Community Enterprise Promotion, Thailand. Definition of community enterprise. 2013; [update 2015 Jun 22; cited 2017 Oct 28]. Available from: www.sceb.doae.go.th/Ssceb2.htm

13. Kongtawelert A, Sujirarat D. Health risk and safety in workplace of informal workers. Buddhachinaraj Med J. 2015; 32(2): 162-70.

14. Noochana K, Arphorn S, Chaikittiphorn C, Kalumpakorn S. Occupational health risk of informal workers in Bangkok. 2014; Graduate Research Conference, Khon Kaen University, MMP77-12, 1759-70.

15. Waeha-yee U, Khongtong P. Health risk in working of the informal workers in Muslim community: case study of Bnagpoo municipality, Yaring district, Phatthani province. SWJST. 2011; 5(3): 59-68.

16. Bua-yom P, Juthong H, Thampalo S, Wiwat L, Kaewpan W. The assessment on health status and health behavior among aging workers in Southern Thailand. Dis con J. 2013; 36(2): 81-9.

17. Fofon S, Theachaboonsermsak P, Pitiguntang S, Charupoonphol P, Kittipichai W. Factors influencing quality of life among street vendors in Bangkok. J Pub Health Dev. 2014; 12(2): 69-83.

18. Kantawanna T. Quality of life of informal-sector workers in Rimping Subdistrict, Mueang Lamphun District. 2007; Chiang Mai University, Chiang Mai.

19. Krejcie RV, Morgan EW. Determining sample size for research activities. Educ Psychol Meas. 1970; 30(10): 608-9.

20. Bureau of Occupational and Environmental Diseases. Health risk assessment form among informal workers. Ministry of Public Health. 2009; [update 2015 Jun 22; cited 2017 Oct 28]. Available from: www2.diw.go.th/envocc/edoc/menu.asp

21. Nilachaikowit T. General Health Questionnaire (Thai-GHQ-28). 2002; Department of Psychiatry, Faculty of Medicine Ramathibodi Hospital, Bangkok.

22. World Health Organization (WHO). WHOQOL BREF introduction, administration, scoring and generic version of the assessment. 1996; [update 1996 Dec; cited 2017 Oct 28]. Available from: www.who.int/mental_health/media/en/76.pdf

23. Mahatnirunkul S, Tuntipivatanakul W, Pumpisanchai W. Comparison of the WHOQOL-100 and the WHOQOL-BREF (26 items). J Ment Health Thai. 1998; 5(3): 4-15.

24. Mahatnirunkul S, Silapakit P, Pumpisanchai W. Quality of life during economic crisis in Thailand. 1998; research report, Suanprung Psychiatric Hospital, Chiang Mai, Thailand: Department of Information Engineering.

25. Suwanakitch P, Luangla P, Romyem S, Tubjig J, Mathapat W. Elderly's quality of life in municipality. Buddhachinaraj Med J. 2013; 30(2): 171-80.

26. Souza LM, Lautert L, Hilleshein EF. Quality of life and voluntary work among the elderly. Rev Esc Enferm USP. 2011; 45(3): 663-9.

27. Bonsang E, Soest AS. Satisfaction with social contracts of older Europeans. Indic Res. 2012; 105: $273-92$.

28. Susilowati IH, Fitria L, Low WY, Kaewboonchoo O, Ratanasiripong P. Predictive factors for quality of life among small and medium enterprise workers in Indonesia. Asian J. Applied Sci. 2017; 10(3) 116-25. 
29. National Statistic Office, Thailand. Elderly: having good mental health when working. 2010; [update 2010 Oct; cited 2017 Oct 28]. Available from: http://service.nso.go.th/nso/web/article/ article_43.html

30. Lu L. Aging and quality of life in Taiwan. J Altern Med Res. 2012; 4(3): 233-43.

31. Steiber N. Aging Workers and the Quality of Life. In: Michalos AC, editor. Encyclopedia of Quality of Life and Well-Being Research. Dordrecht: Springer; 2014.

Corresponding author

Suda Hanklang can be contacted at:Suda_han@vu.ac.th

For instructions on how to order reprints of this article, please visit our website: 